\title{
A one-dimensional model of the evolution of snow-cover characteristics
}

\author{
TAKESHI YAMAZAKI, JUNSEI KONDO, \\ Geophysical Institute, Tohoku University, Sendai 980, Japan \\ TAKASHi SAKURAOKa, \\ Daiwa Sohken, Tokyo 104, Japan \\ TORU NAKAMURA \\ Japan Marine Science and Technology Center, Yokosuka 237, Japan
}

\begin{abstract}
A one-dimensional model has been developed to simulate the evolution of snow-cover characteristics using meteorological data. This model takes into account the heat balance at the snow surface and heat conduction in the snow cover as well as liquid water flow and densification. The basic variables of the model are snow temperature, liquid water content, snow density and the solid impurities density. With these four variables, the model can calculate albedo, thermal conductivity, liquid water flux, snow depth, water equivalent and the amount of runoff.

Diurnal variation of profiles of snow temperature, water content and snow density, and meteorological elements were observed at Mount Zao Bodaira, Yamagata Prefecture, Japan. Simulated diurnal variation patterns of each component by the model were in good agreement with the observations. Moreover, the snow-cover characteristics were simulated for three 90-day periods with meteorological data and snow pit observations at Sapporo. It was found that the model was able to simulate long-period variations of albedo, snow depth, snow water equivalent and the snow density profile.
\end{abstract}

\section{INTRODUCTION}

The characteristics and structures of snow change continually and influence albedo and thermal conductivity, which are important for climate. Snow-cover characteristics are strongly influenced by meteorological conditions. Therefore, we propose a one-dimensional model using meteorological data to simulate the snowcover characteristics for the purpose of clarifying the heat balance and water cycle at the Earth's surface.

There were few all-round snow metamorphism models after a pioneer model developed by Anderson (1976). Recently, Brun and others (1989) proposed an energy and mass model for operational avalanche forecasting, and the model was advanced to take into account grainsize and type of snow (Brun and others, 1992). However, there are few models which can directly predict snow albedo including the effects of solid impurities and liquid water.

\section{BASIC EQUATIONS}

Figure 1 shows the schematic of the physical processes in the model in this paper. All of the physical variables in this model are described by snow temperature $T_{8}$, the amount of liquid water $\rho_{\mathrm{l}}$, the dry snow density $\rho_{\mathrm{dry}}$, and the solid impurities density $\rho_{\mathrm{D}}$ for albedo.

- Snow temperature $T_{\mathrm{s}}$

For a snow surface

$$
\begin{aligned}
C_{\mathrm{s}} \rho_{\mathrm{dry}} \frac{\mathrm{dT}_{\mathrm{s}}}{\mathrm{d} t} \mathrm{~d} z=\left.\lambda_{\mathrm{s}} \frac{\partial T_{\mathrm{s}}}{\partial z}\right|_{z=0} & +\left(\mu I \exp (-\mu z)-l_{\mathrm{f}} F\right) \mathrm{d} z \\
& +\epsilon L^{\downarrow}-\epsilon \sigma T_{\mathrm{sfc}}^{4}-H-l E .
\end{aligned}
$$

In a snow cover

$$
C_{\mathrm{s}} \rho_{\mathrm{dry}} \frac{\mathrm{d} T_{\mathrm{s}}}{\mathrm{d} t}=\frac{\partial}{\partial z}\left(\lambda_{\mathrm{s}} \frac{\partial T_{\mathrm{s}}}{\partial z}\right)+\mu I \exp (-\mu z)-l_{\mathrm{f}} F .
$$

$C_{\mathrm{s}}$ : specific heat of snow; $\lambda_{\mathrm{g}}$ : thermal conductivity of snow; $l_{\mathrm{f}}$ : latent heat of fusion of ice; $F$ : amount of snowmelt per unit time and volume; $I=\left(1-A_{8}\right) S^{\downarrow} ; A_{8}$ : albedo; $S^{\downarrow}$ : solar radiation; $\mu$ : extinction coefficient of solar radiation; $z$ : depth from the snow surface; $L^{\downarrow}$ : downward atmospheric radiation; $T_{\mathrm{sfc}}$ : snow surface temperature; $\epsilon$ : emissivity of snow $(=0.97) ; \sigma$ : StefanBoltzmann constant; $H$ : sensible heat flux; $l E$ : latent heat flux.

- Amount of liquid water $\rho_{\text {lw }}$

$$
\frac{\mathrm{d} \rho_{\mathrm{lw}}}{\mathrm{d} t}=-\frac{\partial Q}{\partial z}+F
$$




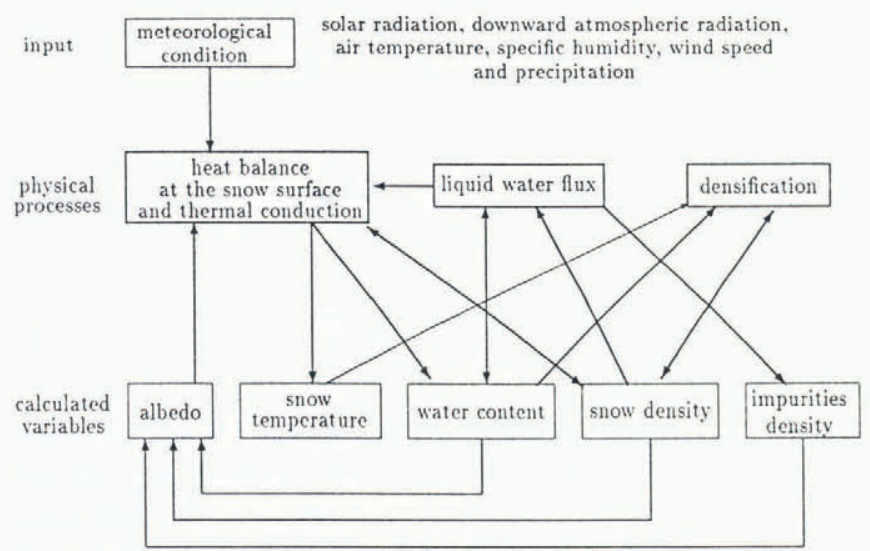

Fig. 1. Schematic of the relation between the physical processes and snow-cover characteristics in this model.

$\rho_{\mathrm{lw}}$ : mass of liquid water per unit volume; $Q$ : downward liquid water flux (Colbeck, 1978; Shimizu, 1970).

- Dry snow density $\rho_{\text {dry }}$

$$
\frac{\mathrm{d} \rho_{\mathrm{dry}}}{\mathrm{d} t}=\frac{W_{\mathrm{s}}}{\eta} \rho_{\mathrm{dry}}-F .
$$

$W_{\mathbf{s}}$ : load; $\eta$ : compactive viscosity coefficient of snow.

- Solid impurities density $\rho_{\mathrm{D}}$

$$
\frac{\mathrm{d} \rho_{\mathrm{D}}}{\mathrm{d} t}=-\frac{\partial}{\partial z}\left(f_{\mathrm{D}} \frac{\rho_{D}}{\rho_{\text {wet }}} Q\right) .
$$

$\rho_{\mathrm{D}}$ : mass of solid impurities per unit volume of snow; $f_{\mathrm{D}}$ : rate of impurities flow; $\rho_{\text {wet }}$ : wet snow density $\left(=\rho_{\mathrm{dry}}+\rho_{\mathrm{lw}}\right)$.

In practice, Equations (1)-(5) are written in differential forms to calculate the profiles of the variables. (A simple version was described in the

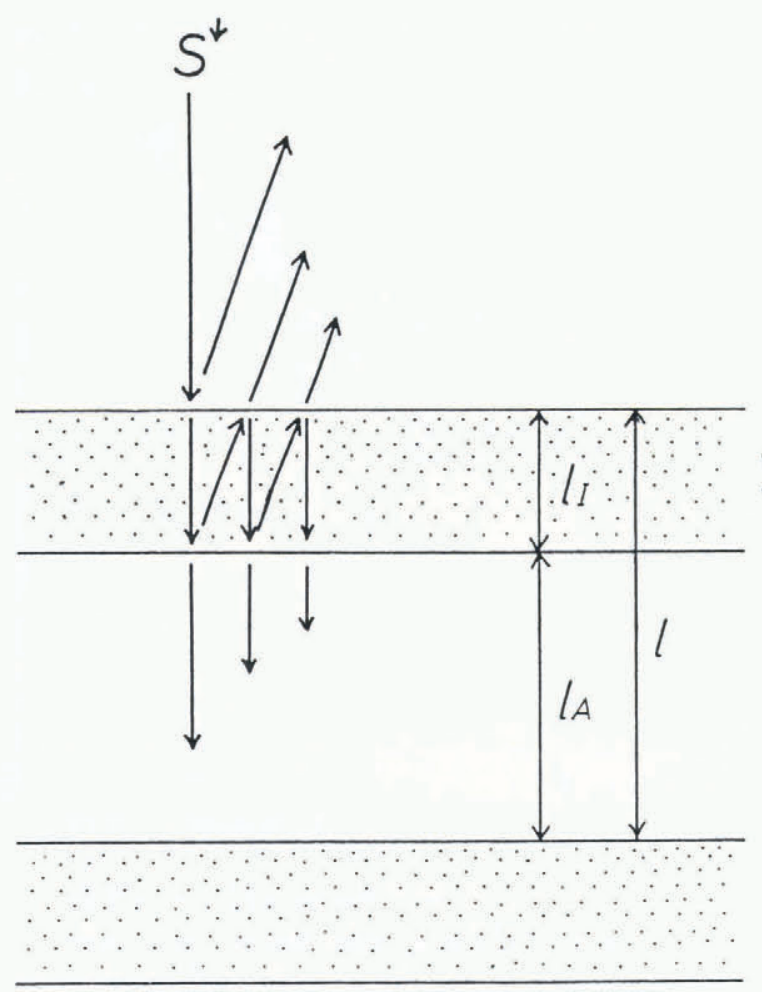

Fig. 2. Schematic of snow albedo submodel. appendix in Kondo and Yamazaki (1990).) The input data are solar and downward radiation, air temperature, specific humidity, wind speed and precipitation. Snowfall and rainfall are distinguished by air temperature $\left(2^{\circ} \mathrm{C}\right)$ in the model. The density of new snow is assumed to be $70 \mathrm{~kg} \mathrm{~m}^{-3}$.

\section{ALBEDO}

The albedo of pure dry snow is obtained from profiles of dry snow density and the optical absorption coefficient of ice (Kondo and others, 1988). The multiple reflection is considered with an assumption that snow is constructed by ice plates and air layers (Fig. 2).

The albedo, $A_{s}$, is obtained by two-stream model as

$$
A_{\mathrm{s}}=r_{\mathrm{I}}+\frac{\left(1-r_{\mathrm{I}}\right)^{2}\left(\beta_{1} D_{1}+\alpha_{1}\right)}{1+D_{1}-r_{\mathrm{I}}\left(\beta_{1} D_{1}+\alpha_{1}\right)},
$$

where

$$
\begin{aligned}
& D_{i}= \\
& \left(\frac{\left.\left(\alpha_{i}-\beta_{i+1}\right) D_{i+1} \exp \left(2 i \Delta z \mu_{i+1}\right)+\alpha_{i}-\alpha_{i+1}\right)}{\left(\beta_{i+1}-\beta_{i}\right) D_{i+1} \exp \left(2 i \Delta z \mu_{i+1}\right)+\alpha_{i+1}-\beta_{i}}\right) \\
& \left(\exp \left(2 i \Delta z \mu_{i}\right)\right) \quad(i=1, \ldots, n-1), \\
& D_{n}=0, \\
& \mu_{i}=\sqrt{A_{i}^{2}-B_{i}^{2}}, \\
& \alpha_{i}=\frac{A_{i}-\mu_{i}}{B_{i}}, \\
& \beta_{i}=\frac{A_{i}+\mu_{i}}{B_{i}}, \\
& A_{i}=\frac{1-T_{\mathrm{I} i} \frac{\rho_{\mathrm{dry}, i}}{\rho_{\mathrm{I}}}}{l_{\mathrm{I} i}} \\
& B_{i}=\frac{\kappa_{\mathrm{I} i}}{\rho_{\mathrm{I} i}} \frac{\rho_{\mathrm{dry}, i}}{\rho_{\mathrm{I}}}, \\
& R_{\mathrm{I} i}=r_{\mathrm{I}}+\frac{\left(1-r_{\mathrm{I}}\right)^{2} r_{\mathrm{I}} \exp \left(-2 k_{\mathrm{I}} l_{\mathrm{I} i}\right)}{1-\left(r_{\mathrm{I}} \exp \left(-k_{\mathrm{I}} l_{\mathrm{I} i}\right)\right)^{2}},
\end{aligned}
$$

and

$$
T_{\mathrm{I} i}=\frac{\left(1-r_{\mathrm{I}}\right)^{2} \exp \left(-k_{\mathrm{I}} l_{\mathrm{I} i}\right)}{1-\left(r_{\mathrm{I}} \exp \left(-k_{\mathrm{I}} l_{\mathrm{I} i}\right)\right)^{2}}
$$

Here, $\mu_{i}$ is the extinction coefficient of solar radiation in $i$-th snow layer, $r_{\mathrm{I}}$ the reflectivity of ice $(=0.018), \rho_{\mathrm{I}}$ the density of ice and $k_{\mathrm{I}}$ the absorption coefficient of ice (assumed to be $10 \mathrm{~m}^{-1}$ ). The thickness of an ice layer $l_{\mathrm{Ii}}$ is obtained as

$$
\begin{gathered}
l_{\mathrm{I} i}=\frac{2}{\rho_{\mathrm{I}} S_{i}^{*}}, \\
\log _{10} S_{i}^{*}=-15.32 \rho_{\mathrm{dry}, i}^{3}+16.65 \rho_{\mathrm{dry}, i}^{2}-7.30 \rho_{\mathrm{dry}, i}+2.23,
\end{gathered}
$$


where $S_{i}^{*}$ is the specific surface area (the area of the surface of the ice particles in unit volume of snow) in $i$-th snow layer. The units of $\rho_{\mathrm{dry}, i}$ and $S_{i}^{*}$ are $\mathrm{g} \mathrm{cm}^{-3}$ and $\mathrm{m}^{2} \mathrm{~kg}^{-1}$, respectively. Equation (8) is an experimental equation based on the data in Narita (1971).

In the model, it is considered that albedo is decreased by the impurities and liquid water content in snow. As the density of the impurities increases, optical absorption coefficient increases. The increase of effective absorption coefficient due to impurities, $k_{\mathrm{D}}$, is assumed to be equal to the cross-section of the impurities per unit volume of ice. Based on a few assumptions for characteristics of impurities, the following equation can be obtained:

$$
k_{\mathrm{D}} \simeq 46 \rho_{\mathrm{D}} \frac{\rho_{\mathrm{I}}}{\rho_{\text {wet }}} .
$$

The units of $k_{\mathrm{D}}$ and $\rho_{\mathrm{D}}$ are $\mathrm{m}^{-1}$ and $\mathrm{kg} \mathrm{m}^{-3}$, respectively. The amount of aerosol fallout is given by $\left(3.14 \times 10^{-8}\right) \beta\left(\mathrm{kg} \mathrm{m}^{-2} \mathrm{~s}^{-1}\right)$, which is obtained from an assumption of the aerosol-size distribution, where $\beta$ is the atmospheric turbidity defined by Yamamoto and others (1968).

The effect of liquid water on albedo is described through a decrease in the specific surface area. That is

$$
S^{*}=S^{*}\left(\rho_{\text {wet }}\right) \cdot f(w),
$$

where

$$
f(w)=1-\gamma w+(\gamma-1) w^{2} .
$$

$w$ is water content $\left(=\rho_{\mathrm{lw}} / \rho_{\mathrm{wet}}\right)$ and $\gamma=1.9$ (Yamazaki and others, 1991). The value of $S^{*}\left(\rho_{\text {wet }}\right)$ is obtained from Equation (8) using $\rho_{\text {wet }}$ instead of $\rho_{\text {dry }}$.

\section{SENSIBLE AND LATENT HEAT FLUX}

Sensible heat $H$ and latent heat $l E$ are written as

$$
H=C_{\mathrm{P}} \rho C_{\mathrm{H}} U\left(T_{\mathrm{sfc}}-T_{\mathrm{a}}\right)
$$

and

$$
l E=l \rho C_{\mathrm{E}} U\left(q_{\mathrm{sat}}\left(T_{\mathrm{sfc}}\right)-q_{\mathrm{a}}\right) .
$$

Here, $C_{\mathrm{P}}$ and $\rho$ are specific heat at constant pressure and density of air, respectively, and $U, T_{\mathrm{a}}$ and $q_{\mathrm{a}}$ are wind speed, air temperature and specific humidity, respectively. The value $q_{\mathrm{sat}}\left(T_{\mathrm{sfc}}\right)$ is the saturated specific humidity at surface temperature $T_{\mathrm{sfc}}$. Bulk coefficients $C_{\mathrm{H}}$ and $C_{\mathrm{E}}$ are set at 0.002 and 0.0021 at a reference height of $1 \mathrm{~m}$, respectively (Kondo and Yamazawa, 1986).

\section{THERMAL CONDUCTIVITY}

The thermal conductivity is parameterized using porosity $P\left(=1-\rho_{\text {dry }} / \rho_{\mathrm{I}}\right)$ as follows.

$$
\lambda_{\mathrm{s}}=P \lambda_{\mathrm{a}}+(1-P) \lambda_{\mathrm{b}},
$$

where $\lambda_{\mathrm{a}}$ is the thermal conductivity of the transverse structure piled by ice plates and air layers same as Figure 1 (the smallest theoretical conductivity), and $\lambda_{b}$ is that of the longitudinal structure (the largest theoretical conductivity). They are written as

$$
\lambda_{\mathrm{a}}=\frac{1}{P / \lambda_{\mathrm{A}}^{\prime}+(1-P) / \lambda_{\mathrm{I}}}
$$

and

$$
\lambda_{b}=P \lambda_{\mathrm{A}}^{\prime}+(1-P) \lambda_{\mathrm{I}},
$$

where

$$
\lambda_{\mathrm{A}}^{\prime}=\lambda_{\mathbf{A}}+L D_{\mathbf{v}} \frac{\mathrm{d} C}{\mathrm{~d} T} .
$$

Here, $\lambda_{I}$ is the thermal conductivity of ice $\left(2.2 \mathrm{~W} \mathrm{~m}^{-1} \mathrm{~K}^{-1}\right), \lambda_{\mathrm{A}}$ the thermal conductivity of air $\left(2.14 \times 10^{-2} \mathrm{~W} \mathrm{~m}^{-1} \mathrm{~K}^{-1}\right), \lambda_{A}^{\prime}$ the effective thermal conductivity of air corrected for vapor diffusion, $L$ the latent heat of sublimation of ice $\left(2.83 \mathrm{MJ} \mathrm{kg}^{-1}\right), D_{\mathrm{v}}$ the diffusion coefficient of water vapor $\left(6.5 \times 10^{-5} \mathrm{~m}^{2} \mathrm{~s}^{-1}\right)$ and $C$ the saturated vapor density.

\section{COMPACTIVE VISCOSITY}

The compactive viscosity coefficient of wet snow is obtained from the equation for dry snow (Kojima, 1957; Shinojima, 1967) using a multiplicative factor which describes the decrease of the compactive viscosity coefficient due to liquid water. That is

$$
\eta=A(w) \eta_{0} \exp \left(K \rho_{\text {dry }}-\alpha_{\mathbf{s}} T_{\mathbf{s}}\right),
$$

where $A(w)$ is assumed as

$$
A(w)=\frac{\exp \left(-\beta_{8} w\right)-\exp \left(-\beta_{8}\right)}{1-\exp \left(-\beta_{8}\right)} .
$$

Here, $\eta_{0}\left(6.9 \times 10^{5} \mathrm{~kg} \mathrm{~s} \mathrm{~m}^{-2}\right), K\left(2.1 \times 10^{-3} \mathrm{~m}^{3} \mathrm{~kg}^{-1}\right)$, $\alpha_{8}\left(9.58 \times 10^{-2}{ }^{\circ} \mathrm{C}^{-1}\right)$ and $\beta_{8}(=18)$ are constants.

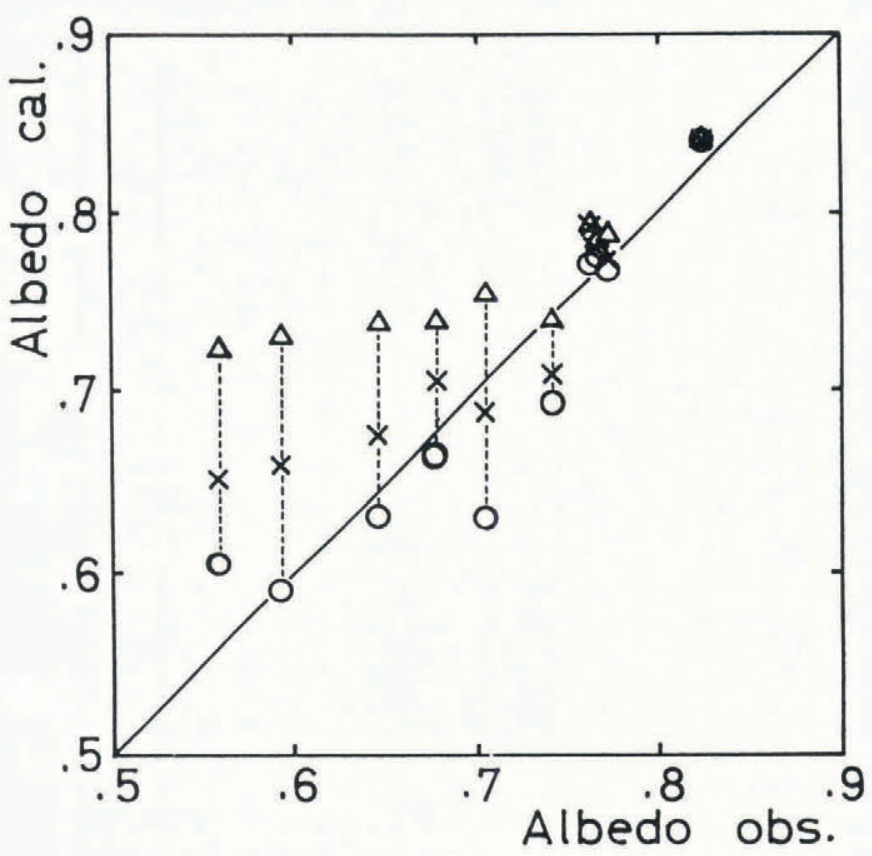

Fig. 3. Comparison of calculated and observed snow albedo at Zao Bodaira. $\triangle$ : effects of impurities or liquid water are not considered; $x$ : taking only impurities into account; O: effects of impurities and liquid water are considered. 


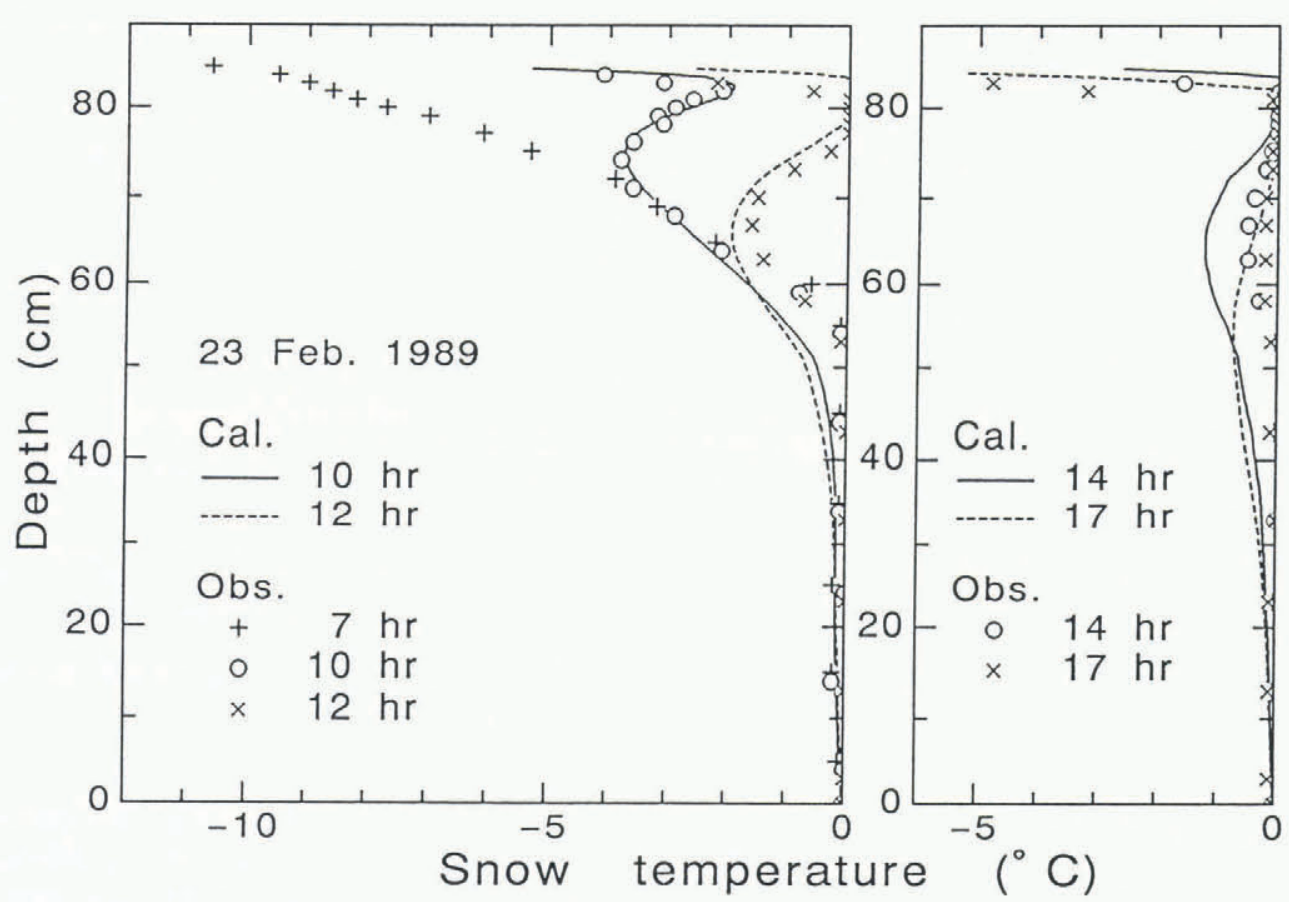

Fig. 4. An example of calculated and observed snow temperature profiles.

\section{SHORT-PERIOD SIMULATION}

Diurnal variation of profiles of temperature, water content and snow density were simulated for the following observation. The detail of the observation has been described in Yamazaki and others (1991).

Period: 23-28 February and 9-15 March 1989.

Place: Mount Zao Bodaira, Yamagata Prefecture, Japan (a flat soil tennis court).

Observations: air temperature, humidity, wind speed, solar radiation, albedo, snow depth, snow type, snow temperature, water content, density and solid impurities density.

Solid impurities density was measured using a method of light absorption (Kondo and others, 1988). The impurity particles are almost mineral. The range of measured absorption coefficients, $k_{\mathrm{D}}$, in the top $5 \mathrm{~cm}$ of the snow cover is from $0.1 \mathrm{~m}^{-1}$ (26 February) to $9.8 \mathrm{~m}^{-1}$ (15 March). Figure 3 displays the values of observed and calculated albedo.

Figure 4 shows the simulated and observed snow temperature profiles for 23 February. The snow temperature was measured using a thermistor thermometer. The solar radiation was shut off with a board at the moment of measurement. The initial profiles of this simulation are given at $0700 \mathrm{~h}$. Diurnal variation patterns of water content are also in agreement with the observations (figure not shown).

\section{LONG-PERIOD SIMULATION}

Period: 1986-1988 (3 winters).

Place: Sapporo, Hokkaido, Japan.

Data: Meteorological data and snow-pit observations at the Institute of Low Temperature Science, Hokkaido University (e.g. Endo and others, 1986; Ishikawa and
Motoyama, 1986) and meteorological data at Sapporo District Meteorological Observatory.

Figure 5 shows the time series of albedo in 1986. The values of important parameters are listed in Table 1 . In this calculation it is assumed that the impurities do not flow out because the value of $f_{\mathrm{D}}$ is set to zero for the snowmelt season. However, the estimated albedo is smaller than the observations (Ishikawa and Motoya$\mathrm{ma}, 1986)$ in the later period. The actual amount of aerosol fallout may be larger than the value which is used in this simulation. At the start of the season, the albedo is slightly underestimated. The reason for this is unclear, however, the observed values in this year are higher than usual.

In Figures 6 and 7 the calculated snow depth and snow water equivalent are compared with the observations (Ishikawa and Motoyama, 1986; Endo and others,

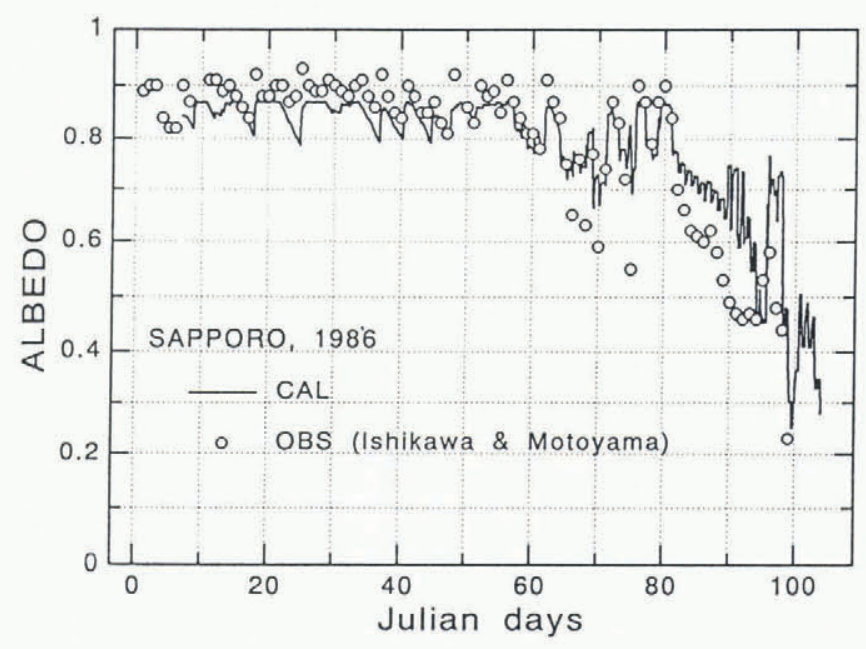

Fig. 5. Comparison of calculated and observed snow albedo for 1986. The observed values are averaged from 1100 to $1200 \mathrm{~h}$ (wave length: $0.29-3.0 \mu \mathrm{m}$ ). 


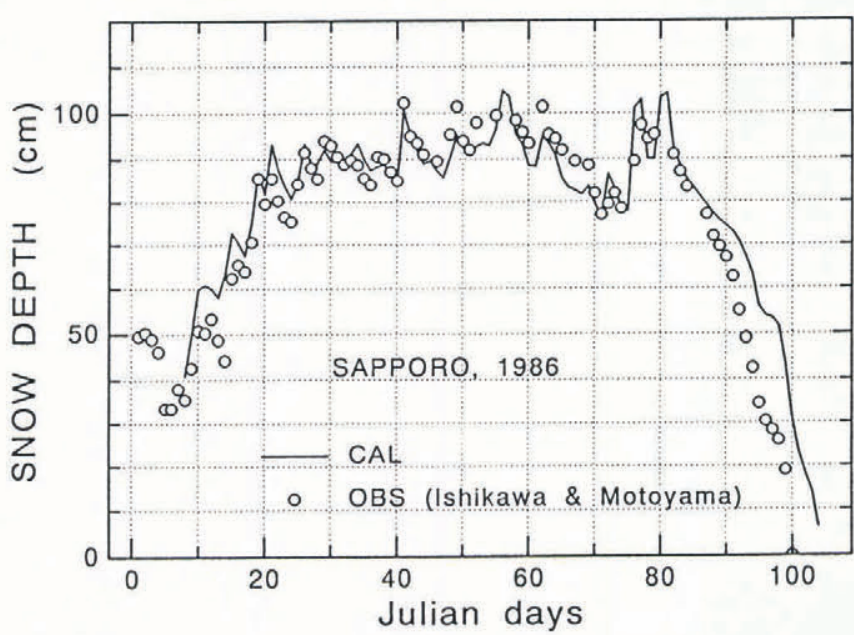

Fig. 6. Comparison of calculated and observed snow depth for 1986 .

Table 1. The list of the main parameters

\begin{tabular}{llll}
\hline & parameter & eq. no. & value \\
\hline & & & \\
$C_{\mathrm{H}}$ & bulk coefficient (sensible) & $(12)$ & 0.002 \\
$C_{\mathrm{E}}$ & bulk coefficient (latent) & $(13)$ & 0.0021 \\
$f_{\mathrm{D}}$ & rate of impurities flow & $(5)$ & 0 \\
$k_{\mathrm{I}}$ & absorption coefficient of ice & $(6)$ & $10 \mathrm{~m}^{-1}$ \\
$\beta$ & atmospheric turbidity & & 0.1 \\
$\mu$ & extinction coefficient & $(1)$ & $40 \mathrm{~m}^{-1}$ \\
\hline
\end{tabular}

1986). The calculated values are overestimated in snowmelt season, because the albedo is large.

\section{CONCLUDING REMARKS}

The evolution of snow-cover characteristics was simulated with a one-dimensional energy balance model. This model includes new parameterizations of the albedo, thermal conductivity and compactive viscosity. In particular, snow albedo was predicted taking into account the effects due to solid impurities and liquid water. The agreement between observed and calculated components was obtained for short- and long-period simulations. However, the handling of impurities requires much more study.

\section{REFERENCES}

Anderson, E. A. 1976. A point energy and mass balance model of a snow cover. NOAA Tech. Rep. NWS 19.

Brun, E., E. Martin, V. Simon, C. Gendre and C. Coleou. 1989. An energy and mass model of snow cover suitable for operational avalanche forecasting. $\mathcal{J}$. Glaciol., 35(121), 333-342.

Brun, E., P. David, M. Sudul and G. Brunot. 1992. A numerical model to simulate snow-cover stratigraphy for operational avalanche forecasting. 7. Glaciol., 38(128), 13-22.

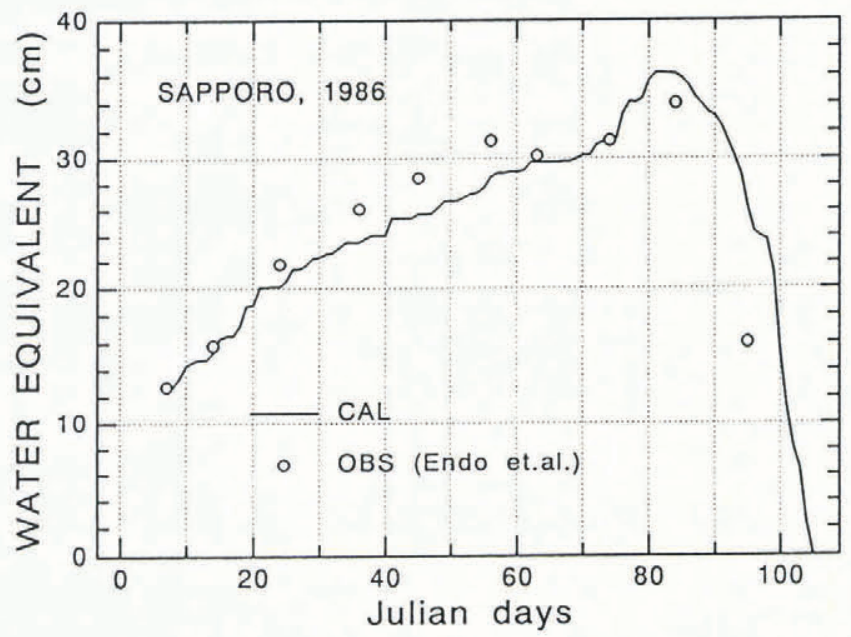

Fig. 7. Comparison of calculated and observed snow water equivalent for 1986 .

Colbeck, S. C. 1978. The physical aspects of water flow through snow. Adv. Hydrosci. 11, 165-206.

Endo, Y., E. Akitaya and Y. Mizuno. 1986. Report of pitwall observations of snow cover in Sapporo 1985-86. Low Temp. Sci., Ser. A 45, Data Rep., 1-10. [In Japanese.]

Ishikawa, N. and H. Motoyama. 1986. Radiation measurements of snowy season in 1986 at Sapporo. Low Temp. Sci., Ser. A 45, Data Rep., 17-23. [In Japanese.]

Kojima, K. 1957. Viscous compression of natural snow layers III. Low Temp. Sci., Ser. A 16, 167-196. [In Japanese with English summary.]

Kondo, J. and T. Yamazaki. 1990. A prediction model for snowmelt, snow surface temperature and freezing depth using a heat balance method. 7. Appl Meteorol., 29(5), 375-384.

Kondo, J. and H. Yamazawa. 1986. Bulk transfer coefficient over a snow surface. Boundary-Layer Meteorol., 34(1-2), 123-135.

Kondo, J., Y. Numata and T. Yamazaki. 1988. Parameterization of snow albedo. Seppyo. Journal of the Japanese Society of Snow and Ice, 50(4), 216-224. [In Japanese with English summary.]

Narita, H. 1971. Specific surface of deposited snow II. Low Temp. Sci., Ser. A 29, 69-79. [In Japanese with English summary.]

Shimizu, H. 1970. Air permeability of deposited snow. Contrib. Inst. Low Temp. Sci., Ser. A 22. 1-32.

Shinojima, K. 1967. Study on the visco-elastic deformation of deposited snow. In Ōura, H., ed. Physics of snow and ice. Sapporo, Hokkaido University. Institute of Low Temperature Science, 875-907.

Yamamoto, G., M. Tanaka and K. Arao. 1968. Hemispherical distribution of turbidity coefficient as estimated from direct solar radiation measurements. $\mathcal{J}$. Meteorol. Soc. Jpn., 46, 287-300.

Yamazaki, T., T. Sakuraoka, T. Nakamura and J. Kondo. 1991. A study of snow metamorphism. Seppyo. Journal of the Japanese Society of Snow and Ice, 53(2),115-133. [In Japanese with English summary.]

The accuracy of references in the text and in this list is the responsibility of the authors, to whom queries should be addressed. 